\title{
Erratum to: English for Scientific Purposes (EScP): Technology, Trends, and Future Challenges for Science Education
}

\author{
Gi-Zen Liu ${ }^{1,2} \cdot$ Wan-Yu Chiu ${ }^{1}$ Chih-Chung $\operatorname{Lin}^{1} \cdot$ Neil E. Barrett ${ }^{1,3}$
}

Published online: 4 April 2015

(c) Springer Science+Business Media New York 2015

\section{Erratum to: J Sci Educ Technol (2014) 23:827-839 DOI 10.1007/s10956-014-9515-7}

In the original publication, there are five typos in numerical representation within this paper. Therefore, the authors would like to make the following changes:

1. On page 830, the corrected sentence should be: "After the detailed search, a total of 12 papers were found to meet the criteria needed for this review."

2. On page 831: the following are the corrected sentences,

i. "Figure 5 shows the distribution of LT used in the 12 studies."

ii. "Three of the 12 studies were related to LT, while only 5 studies discussed the implications for EScP instructors."

iii. Figure 3, "Target papers: 12 studies."

iv. The last sentence: software (14\%, 1 study).

The authors sincerely apologize to readers for the typo errors.

The online version of the original article can be found under doi:10.1007/s10956-014-9515-7.

Gi-Zen Liu

gizen@mail.ncku.edu.tw; gizenliu@gmail.com

1 Department of Foreign Languages and Literature, National Cheng Kung University, 1, University Road,

Tainan City 701, Taiwan

2 Foreign Language Center, National Cheng Kung University, 1, University Road, Tainan City 701, Taiwan

3 English Language Center, Southern Taiwan University of Science and Technology, N Building No. 1, Nan-Tai Street, Yungkang Dist., Tainan City 710, Taiwan 